\title{
Dilemas éticos em UTI: contribuições da Teoria dos Valores de Max Scheler
}

\author{
Ethical dilemmas in ICU: contributions of Max Scheler's Theory of Values
}

Dilemas éticos en UTI: contribuciones de la Teoría de Valores de Max Scheler

\author{
Marlise Barros de Medeiros', Eliane Ramos Pereira", \\ Rose Mary Costa Rosa Andrade Silva", Marcos Andrade Silva"l' \\ 'Instituto Nacional do Câncer, Programa de Residência em Enfermagem em Oncologia. Rio de Janeiro-RJ, Brasil. \\ "Universidade Federal Fluminense, Departamento de Enfermagem Médico-Cirúrgica. Niterói-RJ, Brasil. \\ I"' Universidade Gama Filho, Departamento de Enfermagem. Rio de Janeiro-RJ, Brasil.
}

Submissão: 28-09-2010

Aprovação: 12-04-2012

\section{RESUMO}

O estudo objetivou refletir, tomando como base o referencial teórico de Max Scheler, sobre os dilemas éticos vivenciados por enfermeiros na UTI, e sobre os valores que norteiam suas atitudes e decisões. Trata-se de pesquisa qualitativa, tendo sido entrevistados dez enfermeiros da UTI de um hospital universitário. Identificou-se a vivência de dilemas éticos referentes à terminalidade relacionada aos limites de intervenções e de utilização dos recursos materiais, além da questão da transfusão de sangue em caso de restrição religiosa. Os valores identificados foram: respeito, dignidade do paciente, conhecimento científico, humildade, paixão pela profissão e amor a Deus. A teoria dos valores constitui importante subsídio para enfermagem por permitir a abordagem de uma ética humanizadora da práxis, especialmente nas situações de dilemas éticos.

Descritores: Filosofia em enfermagem; Ética profissional; Unidades de Terapia Intensiva; Ética baseada em princípios.

\begin{abstract}
The study aimed to reflect, based on the theoretical framework of Max Scheler, about the ethical dilemmas experienced by nurses in the ICU, and about the values that guide their actions and decisions,. This is qualitative research, and ten ICU nurses have been interviewed at a university hospital. It was identified the experience of ethical dilemmas related to the terminality related to the limits of intervention and use of material resources, as well as the issue of blood transfusion in case of religious restrictions. The values identified were: respect, dignity of the patient, scientific knowledge, humility, passion for the profession and love of God. The theory of values is an important tool for nursing because it allows the approach of an ethics of humanizing praxis, especially in situations of ethical dilemmas.
\end{abstract}

Key words: Philosophy nursing; Professional ethics; Intensive Care Units; Principle-based ethics.

\section{RESUMEN}

El objetivo del estudio fue reflexionar, con base en el marco teórico de Max Scheler, sobre los dilemas éticos experimentados por enfermeros en la $\mathrm{UCl}$, y sobre los valores que orientan sus actitudes y decisiones,. Se trata de investigación cualitativa y fueran entrevistados diez enfermeros de la UCI de un hospital universitario. Identificada la experiencia de los dilemas éticos relativos a la condición terminal sobre los límites de la intervención y el uso de los recursos materiales, más allá de la cuestión de la transfusión de sangre en caso de restricciones religiosas. Los valores identificados fueron: el respeto, la dignidad del paciente, el conocimiento científico, la humildad, la pasión por la profesión y el amor de Dios. La teoría del valor constituye un instrumento importante para la enfermería, permitiendo el uso de una ética humana de la práctica en situaciones de dilemas éticos.

Palabras clave: Filosofía en Enfermería; Ética Profesional; Unidades de Cuidados Intensivos; Ética Basada en Principios. 


\section{INTRODUÇÃO}

A terminalidade da vida no contexto do avanço biotecnológico tornou-se uma problemática significativa para os profissionais de saúde ${ }^{(1)}$. A bioética, entendida como a ética aplicada à vida em um contexto social ${ }^{(2)}$, permitiu o surgimento do pensamento reflexivo como base para nortear as condutas terapêuticas e a tomada de decisão frente aos dilemas éticos presentes nas diversas áreas de atuação dos profissionais de saúde. O dilema ético em certa medida configura-se como quebra do isolamento da própria consciência e a reconquista da relevância da práxis livre e autônoma.

Os dilemas éticos podem ser entendidos como a necessidade de escolha entre duas ou mais alternativas, igualmente desejáveis ou indesejáveis, passíveis de questionamento moral, sendo necessários a reflexão e o diálogo transdisciplinar para tomada de decisão, pois não há resposta pronta, conduta preestabelecida ou valores absolutos ${ }^{(1,3)}$.

As Unidades ou Centros de Terapia Intensiva apresentam, peculiarmente, os dilemas éticos relacionados aos limites de ação terapêutica envolvidos com a pluralidade dos valores das pessoas envolvidas ${ }^{(1)}$. Estas unidades, que são destinadas ao atendimento de pacientes graves ou de risco de morte ${ }^{(4)}$, apresentam aparatos tecnológicos e cuidados complexos que podem promover a estabilização de quadros clínicos graves, salvando vidas, ou podem promover o prolongamento do processo de morte de pacientes gerando sofrimento e ansiedade para o paciente, para familiares e para a equipe multiprofissional, especialmente para a enfermagem. O prolongamento exagerado da morte, quando a mesma é inevitável, causando ansiedade e sofrimento é conhecido como distanásia, também é compreendido como tratamento fútil ou obstinação terapêutica ${ }^{(5)}$.

O dilema ético está permeado pela cultura, filosofia e pelos valores que baseiam as mesmas. A pluralidade dos diferentes contextos culturais de uma sociedade que são constituídas de indivíduos que hierarquizam seus valores de maneira singular baseados pela autonomia permite constantes indagações sobre as questões que envolvem a vida e, principalmente, sua terminalidade.

A negociação de valores, nestas situações, permite que os direitos e os deveres dos envolvidos sejam cumpridos e que a solução escolhida garanta mais benefícios do que malefícios. Isso exige profissionais de saúde comprometidos com a ética, e capazes de permitir a existência do diálogo multidisciplinar e a participação da família para tomada de decisão, porém a participação do enfermeiro no processo de tomada de decisão em situações que envolvem dilemas éticos ainda apresenta uma série de obstáculos como o despreparo para desenvolver o diálogo multiprofissional, o distanciamento de profissionais devido ao sofrimento emocional que tais situações podem acarretar e o comportamento passivo ou alienação que pode ser um indício do desconhecimento a respeito da ética e da falta de reflexão sobre os próprios valores morais que torna qualquer profissional incapaz de identificar e negociar valores em um contexto social( ${ }^{(6)}$.

Tais obstáculos apresentam, como consequências, a insatisfação, angústia, índices de Burnout, e é fato que o sofrimento moral acarreta consequências significativas para os enfermeiros $^{(7)}$. O enfermeiro é um sujeito que busca, naturalmente, realizar-se como profissional e como indivíduo. Os dilemas e conflitos são um entrave para a conquista da realização profissional e para a conquista da qualidade da assistência, pois uma depende da outra e são requisitos para a qualidade total de uma instituição ${ }^{(8)}$.

Este estudo surgiu a partir das experiências e reflexões proporcionadas no ambiente hospitalar. O objeto deste estudo são as possibilidades de vivência de dilemas éticos pelos enfermeiros da Unidade de Terapia Intensiva (UTI) de um Hospital Universitário sob a perspectiva filosófica de Max Scheler. Para nortear esta reflexão formularam-se as seguintes questões: Os enfermeiros vivenciam dilemas éticos? Quais? Que valores norteiam suas atitudes e decisões?

Como objetivo deste estudo tem-se o de refletir sobre os dilemas éticos vivenciados por enfermeiros na Unidade de Terapia Intensiva, e os valores norteiam suas atitudes e decisões tomando como base o referencial teórico de Max Scheler. O estudo torna-se relevante tendo em vista a ocorrência de diversas situações de conflitos éticos que o profissional de saúde enfrenta. Além disso, ressalta-se a necessidade de uma educação intensiva e contínua dos médicos e enfermeiros em ética ${ }^{(9)}$, pois "a ética é um fazer, é uma ocupação, que é preciso conhecer para ser levada a cabo com êxito. É uma tarefa dos indivíduos, dos povos e das organizações, que pretendem com isso alcançar sua plenitude ou, o que é idêntico, sua felicidade"(10).

As contribuições desse referencial no contexto da ética profissional são de suma importância na medida em que para o avanço do saber faz-se necessário a troca de visadas com outras disciplinas, configurando-se como intercessão de variadas instâncias, já que a expressiva produção do saber da enfermagem firmadas na intercessão de instâncias interdisciplinares e na pluralidade do conhecimento científico, tem sobrepujado muitos paradigmas e desafios na profissão. ${ }^{(11)}$

\section{REFERENCIAL FILOSÓFICO}

A teoria dos valores de Max Scheler aborda sobre a objetividade dos valores e seu processo de apreensão de caráter emocional. Através da percepção emocional afetiva pura se dá o acesso ao mundo dos valores éticos que estão fundados no conhecimento do bem e moldam a conduta do homem. Para Scheler os valores existem a priori, existem de forma objetiva, são independentes de qualquer pessoalidade dos sujeitos que os portam, mas são apreendidos através de um processo emocional(12). O sujeito precisa viver uma experiência que o levará ao conhecimento do valor, de sua essência, que é captada através da intuição emocional, que também é denominada "emoção pura" definida por Scheler como um dom superior. A partir dessa premissa afirma-se que a racionalidade não é capaz de abarcar em si toda amplitude da realidade ${ }^{(13)}$.

$\mathrm{Na}$ medida em que os valores são conhecidos por cada sujeito a sua incorporação exige sempre uma reorganização de sua hierarquia. Os valores, em Scheler ${ }^{(14)}$, são hierarquizados em categorias do inferior ao superior, e compreendidos por antíteses da seguinte forma: 1. Valores sensíveis (alegria-tristeza, dor-prazer); 2. Valores da civilização (útil-danoso); 3. 
Valores vitais (nobre-vulgar); 4. Valores espirituais ou culturais que incluem: Valores estéticos (belo-feio), Valores ético-jurídicos (justo-injusto) e Valores especulativos (verdadeiro-falso); 5. Valores religiosos (sagrado-profano).

A partir da hierarquização dos valores o indivíduo constrói o seu ethos. Na medida em que se adquirem novos valores essa hierarquia é reorganizada. A pessoa adquire os valores e o seu conteúdo apriorístico através de uma intuição emocional. Como a liberdade é imprescindível para a ética, na medida em que um indivíduo possui valores ele mesmo pode preferir ou preterir esses valores. "O valor superior é captado como tal pelo ato de preferência e o inferior pelo ato de preterição"(12). Depreende-se, a partir da leitura em Scheler, que os valores sensíveis são importantes, entretanto encerram-se em si mesmos não contemplando o homem por inteiro, por isso considera que uma ética baseada só nos bens materiais e sensíveis acaba provocando o esvaziamento do homem interior.

Na perspectiva scheleriana, só através do amor podemos chegar à realidade da pessoa que constitui o núcleo ontológico do outro. Por outros meios, como os racionais e científicos, podemos conhecer o caráter, o temperamento, nunca a pessoa do outro. Por estes métodos, não identificamos a pessoa, mas somente dados, sinais e particularidades e se ignora a que indivíduo pertencem ${ }^{(12)}$. No pensar de Scheler, destaca-se que "a pessoa individual não nos é dada senão no ato de amor, e seu valor, enquanto valor individual não se nos revela senão através desse ato"(15:318).

Nesse sentido, para cuidar é preciso conhecer o outro, o paciente, o familiar, os profissionais, e estes não são constituídos somente por dados lógicos, mas também por uma série de subjetividades, dentre elas, os valores. E, para que esses valores sejam identificados, é preciso que exista uma relação permeada pelo amor, que se torna a motivação para o agir, com base nos valores éticos. Para a enfermagem, as premissas do pensamento de Scheler podem contribuir significativamente na prática do cuidado, fortalecendo filosoficamente a sua essência, subsidiando o exercício de uma ética baseada em princípios e, assim, aprofundar estudos sobre a temática.

\section{METODOLOGIA}

Trata-se de um estudo descritivo, de abordagem qualitativa, modalidade esta que permite compreender um problema da perspectiva dos sujeitos que o vivenciam, ou seja, parte de sua vida diária, sua satisfação, desapontamentos, surpresas e outras emoções e sentimentos ${ }^{(16)}$.

A coleta de dados foi por meio de entrevista focalizada, visando buscar dos enfermeiros, a narrativa de fatos que demonstrem a vivência de dilemas éticos. O instrumento de coleta de dados foi elaborado com questões norteadoras as quais permitiram que o entrevistado pudesse expressar sem restrições suas experiências cabendo ao entrevistador somente nortear o diálogo: 'Você vivencia algum dilema ético? Caso sim, quais? Que valores norteiam suas atitudes e decisões?'

O cenário da pesquisa foi a Unidade de Terapia Intensiva de um Hospital Universitário em Niterói-RJ, no período de junho a agosto do ano de 2009. Os sujeitos da pesquisa foram
10 enfermeiros com atuação profissional em UTI. Os critérios de inclusão adotados foram que os enfermeiros tivessem mais de um ano de experiência profissional em Unidade de Terapia Intensiva e aceitassem participar da pesquisa.

As entrevistas foram gravadas, após o devido preenchimento do Consentimento Livre e Esclarecido pelos enfermeiros a serem entrevistados, e posteriormente foram transcritas na íntegra. Os dados foram coletados tendo sido resguardada a liberdade do entrevistado em deixar de participar da pesquisa, sem prejuízo de qualquer ordem.

Os enfermeiros entrevistados possuiam faixa etária entre 24 e 48 anos, sendo oito do sexo feminino e dois do sexo masculino, e todos tinham mais de um ano de experiência em UTI. Os enfermeiros exerciam, no período, atividades gerenciais de coordenação, como diaristas ou plantonistas. A pesquisa respeitou as determinações da Resolução 196/96/ CNS, tendo sido aprovada no Comitê de Ética e Pesquisa do Hospital Universitário Antônio Pedro, mediante CEP CMM/ HUAP n070/09, e Protocolo CAAE n 0054.0.258.000-09. Os dados foram analisados e categorizados, sendo amparados teoricamente a partir do referencial de Max Scheler.

\section{RESULTADOS E DISCUSSÃO}

As categorias que emergiram no estudo foram sobre "a vivência de dilemas éticos" e "os valores norteadores dos enfermeiros". Os dilemas vivenciados foram concernentes à terminalidade, no que se refere aos limites de intervenções terapêuticas, utilização dos recursos materiais e transfusão de sangue, em caso de restrição religiosa. Os valores que permeiam os dilemas éticos vivenciados pelos enfermeiros foram identificados e classificados conforme a hierarquia da Teoria dos Valores da seguinte forma: o amor pela profissão, evidenciado como um dos valores sensoriais; a humildade, como um dos valores vitais; o respeito, a dignidade, a justiça, constituindo valores ético-jurídicos no âmbito dos valores culturais ou espirituais, além do conhecimento científico, como valor lógico; e, finalmente o amor a Deus, dentre os valores religiosos.

\section{A VIVÊNCIA DE DILEMAS ÉTICOS}

Os dilemas éticos são caracterizados pela necessidade de optar por uma determinada alternativa dentre outras, onde haverá resultados igualmente desejáveis ou indesejáveis, sendo imprescindível a reflexão de cada situação em específico. Para os dilemas éticos não há resposta pronta, conduta preestabelecida ou valores pré-determinados ${ }^{(3)}$. As decisões podem ser justificadas tecnicamente, porém são passíveis de questionamento, onde os valores estão envolvidos. Os enfermeiros entrevistados relataram que vivenciaram situações de dilemas éticos.

\section{O dilema da conduta terapêutica estabelecida em pacien- tes terminais na UTI}

Algumas apreensões apontam haver conflitos em relação a determinadas condutas no exercício profissional, no diálogo interdisciplinar entre médicos e enfermeiros, especialmente no que se refere à diferenças de abordagens no cuidado. 
Aquele conflito entre os profissionais onde às vezes a enfermagem acha que tem que ter uma conduta com o doente e o médico acha que tem que ter uma outra conduta. Os dilemas éticos são mais nesses sentidos. E1

Você tem certeza que você quer aumentar a noradrenalina desse paciente, tem certeza que é isso que você vai fazer? Não é que eu preferia que ele morresse, mas porque olhar para ele daquela forma, e depois para família enterrar seu ente querido e olhar para ele roxo. E2

Eu tenho plantonistas que antes do doente parar (parada cardiorrespiratória) ele fala 'não tem porque fazer manobra de ressuscitação nesse paciente', ok, fechou ali. [...]. E temos aquele dilema: fazer ou não fazer? Você está fazendo alguma coisa viável, você está prorrogando a vida dele, você está aumentando o sofrimento dele? E6

O dilema ético que eu vivencio lá é o investimento excessivo em pacientes terminais, por exemplo, o uso excessivo de nora [...] sabemos que está errado, mas ficamos de mãos atadas, porque se não aumentar irão nos cobrar. E9

Não existe um consenso a respeito das medidas terapêuticas aos pacientes terminais, o que de fato caracteriza as situações apresentadas como um dilema ético, ou seja, cada situação deve ser pensada unicamente, pois não há uma conduta preestabelecida e qualquer decisão que for tomada acarretará um resultado desfavorável. Outrossim, dentre as opções, deve ser escolhida a que menos causará consequências danosas ao paciente, respeitando os princípios éticos das pessoas envolvidas. Existem discussões a respeito da distanásia, que significa o prolongamento exagerado da morte de um paciente causando ansiedade e sofrimento, compreendido como tratamento fútil, quando as condutas terapêuticas, que visam salvar a vida do paciente terminal, e causam grande sofrimento por prolongar o processo de morte. A distanásia tornou-se um dilema ético e considera-se uma obrigação moral parar o que é medicamente fútil e oferecer conforto e amenização do sofrimento ${ }^{(2)}$.

Pode-se destacar que os enfermeiros consideram mais importante a dignidade do paciente e assumem uma postura mais ética em relação à vida do paciente considerado terminal na UTI. Os profissionais determinam o que é necessário e o que é fútil com base em seus valores.

\section{O dilema da utilização de recursos materiais e infra-estrutura}

Outro dilema ético mencionado pelos enfermeiros está relacionado ao uso da tecnologia, seja de que ordem for, empregada em pacientes considerados graves com menos chances de responder ao tratamento empreendido.

Os nossos dilemas são em relação ao material, ao quantitativo de material, à insuficiência de determinadas coisas que a gente tem que escolher pra quem vai. E1

[...] um medicamento caríssimo, o médico diz que o paciente vai se beneficiar com este medicamento e aí você fica na dúvida, não é toda hora que você tem isso no hospital e então, faz ou não faz? Isso eu estou falando de uma pessoa idosa, noventa e oito anos, diabética, cheia de comorbidades, não estou falando de um cliente jovem, nós temos vários parâmetros a estar trabalhando... mas, por outro lado, isso me aflige, eu vou estar usando um dos poucos recursos que o hospital tem para um paciente que tudo me leva, tudo me indica que ele não vai responder, e normalmente ele não responde. E10

É notável que todos os dilemas éticos categorizados em discordância sobre as condutas terapêuticas estabelecidas aos pacientes terminais e sobre o uso dos recursos materiais estão intimamente relacionados. O dilema entre usar ou não usar um material está relacionado, também, à discordância sobre uma terapêutica estabelecida que tenha sido julgada como ineficaz ou fútil diante da finitude da vida do paciente.

Os recursos materiais, a tecnologia, devem ter sua utilização direcionada ao beneficio da dignidade humana, do homem interior e não em beneficio de interesses da organização do homem, isto é, de interesses centrados nos aspectos físicos, biológicos e materiais presentes no modelo biomédico e hospitalocêntrico. Na Teoria dos Valores, as vantagens e os benefícios da tecnologia "dependem apenas da sua correta orientação e compreensão, na medida em que a transformação, o domínio e o controle da natureza externa forem colocados a serviço da vida interior do espírito e não apenas em função dos interesses da organização psicofísica do homem"(12).

$\mathrm{O}$ enfermeiro gerencia os recursos materiais para prestar assistência direta aos pacientes, por isso na fala da E1, da E6 está evidenciada a preocupação com a falta de material, pois se há pouco deve ser usado nos casos em que haverá beneficio e não o desperdiço de materiais e exposição de pacientes a medidas terapêuticas ineficazes. Esse dilema aparece também na fala de E8 ao relatar a impossibilidade de atender pacientes viáveis pela ocupação dos leitos da UTI com pacientes terminais. As Unidades de Terapia Intensiva são as que possuem os custos mais altos dentro de um hospital ${ }^{(17)}$ e é destinado ao tratamento de pacientes que apresentam alta possibilidade de cura e reabilitação através do uso das tecnologias presentes neste setor. Surge então o dilema:

[...] o que mais me conflita aqui no CTI é a clientela a qual é atendida, porque geralmente são pacientes que não tem prognóstico muito bom e às vezes você deixa de ter vaga para paciente viável... então quando chega um paciente que realmente precisaria de uma unidade de terapia intensiva não há leito. E8

Identifica-se então o mau uso dos recursos materiais disponíveis, ou seja, da capacidade tecnológica da UTI, associado ao investimento em pacientes que necessitavam de outra conduta terapêutica. Nesse aspecto, é interessante considerar que o progresso industrial não tem valor senão sob a condição de não atentar de um modo permanente contra os valores vitais ${ }^{(18)}$, entendendo-se o avanço industrial como avanço técnico científico. O aparato tecnológico presente na UTI é 
extremamente útil, pois pode salvar a vida de um paciente. Porém existem pacientes que, devido à sua condição física e ao processo patológico, evoluem para o processo inevitável da morte. Um diálogo aberto entre a equipe multidisciplinar possibilita identificar o momento em que a cura não é mais possível e então iniciar uma assistência adequada.

Os cuidados paliativos como analgesia, suporte ventilatório, podem ser realizados em uma unidade de cuidados paliativos. A elaboração de um protocolo de administração de noradrenalina evitaria seu uso indiscriminado e obstinado. Estas sugestões surgiram nos discursos dos enfermeiros demonstrando que esses profissionais possuem uma ética cujos valores vitais e espirituais orientam a utilização dos recursos materiais o que os torna capazes de direcionar o uso da tecnologia de maneira justa. Numa abordagem transdisciplinar, a conduta terapêutica não seria decidida somente pela equipe médica, e com a participação da enfermagem, os cuidados não constituiriam apenas num suporte para medidas curativistas.

\section{O dilema da transfusão de sangue em paciente com res-} trições religiosas

A situação de necessidade de transfusão de sangue em pacientes que pertencem a determinado segmento religioso com restrições nessa conduta, constitui um dos dilemas éticos mais discutidos em literaturas. No relato de um dos enfermeiros, o paciente era menor de idade, e os pais não permitiam a transfusão que salvaria a vida da criança:

[E5] teve assim, um caso em que os pais de uma criança não queriam autorizar a transfusão de sangue pra salvar a vida do próprio filho, e essa situação causou um conflito ético muito grande que vivenciei.

Tem sido estabelecida uma conduta padronizada que leva a transfusão de sangue ao paciente mesmo sem o consentimento do mesmo, pois o direito à vida é bem jurídico de maior relevância não podendo ser transgredido pela liberdade da própria pessoa ${ }^{(19)}$. Na prática médica, é vedado desrespeitar o direito do paciente ou de seu representante legal de decidir livremente sobre a execução de práticas diagnósticas ou terapêuticas, salvo em caso de iminente perigo de vida ${ }^{(20)}$. No exercício da Enfermagem, o enfermeiro deve respeitar, reconhecer e realizar ações que garantam o direito da pessoa, de tomar decisões sobre sua saúde, tratamento, conforto e bem estar. Além dessa prerrogativa, é proibido ao enfermeiro executar ou participar da assistência à saúde sem o consentimento da pessoa ou de seu representante legal, exceto em iminente risco de morte ${ }^{(21)}$.

Mesmo com controvérsias em relação a essa conduta que limita a autonomia individual em favor dos valores fundamentais estabelecidos pela sociedade, o Dever, outras religiões acreditam que é uma questão de coerência defender a vida em primeiro lugar, pois é deste princípio fundamental que se justifica a defesa dos demais direito, como o de possuir qualquer tipo de crença. Na hierarquia dos valores, os valores religiosos e espirituais são colocados em primeiro lugar, porém o retrato de nossa atual sociedade não apresenta essa hierarquia de valores. O Estado é dito como laico e determina juridicamente que os valores religiosos não podem interferir no direito a vida. É preciso também compreender que o dilema ético também está relacionado e atravessado pela cultura que os sujeitos estão inseridos. A cultura para a Teoria dos Valores seria, portanto uma categoria do ser, não do saber e da experiência ${ }^{(22)}$.

\section{OS VALORES NORTEADORES DOS ENFERMEIROS}

Em meio aos dilemas, alguns valores que norteiam as condutas dos enfermeiros no cuidado ao paciente crítico são fundamentais, são apontados, indicando uma ética pautada em princípios.

\section{O amor pela profissão como valor sensível e a humildade como valor vital:}

Pela ética material dos valores, os bens são fatos e os valores, essências. A paixão é um valor sensorial que norteia a prática profissional: [E2]Sou assim apaixonada pela minha profissão, amo o que eu faço amo de paixão. Por outro lado, é na existência, no mundo, que a pessoa está originariamente em relação com o eu-do-outro e assim é neste encontro que poderá ocorrer a emergência dos valores vitais, como, por exemplo, a humildade. [E10][...] humildade para aceitar crítica também, a humildade pra ouvir. Sendo a humildade uma reação, atitude sentimental, ela é considerada um valor vital.

\section{O respeito, a dignidade e a justiça: valores ético-jurídicos no cuidado ao paciente na UTI}

O enfermeiro, desde sua formação, é apresentado e confrontado com a questão ética que é atravessada por uma série de valores relacionados ao respeito pelo outro, dignidade, sobretudo em relação aos cuidados e também com relação ao senso de justiça e consciência do dever cumprido:

Primeiramente, eu viso à qualidade da assistência, meu foco é no paciente. Respeito ao paciente. E4

Acima de tudo, o respeito, e também ter um nível de conhecimento. A partir do momento que você conhece sobre várias coisas, sobre religião, sobre cultura, em que você passa a respeitar a pessoa, você se torna mais responsável nas suas decisões [...]. Porque se você não conhece o valor de cada cultura de certas pessoas, da religião você não vai respeitar, você vai negligenciar aquilo e tomar a conduta que você acha que é certa. E5

Para tomar uma decisão, o primeiro conceito pilar, norteador é a questão da dignidade e do respeito e aí eu vou tentar aliar isso ao conhecimento científico. Em alguns momentos, a gente percebe que ele não está interagindo, mas de alguma forma isso pode ser muito bom para o paciente, e aí você vai liberar pela questão da dignidade, respeito eu acho que é o principal e, é lógico, nunca deixar de aliar isso ao conhecimento científico. E6 
Meus valores [...], a função da Unidade de Terapia Intensiva, ela deve se usada para casos que podem ser revertidos. E7

[...] os valores que eu trago são os valores de respeito de tratar bem as pessoas, fazer o melhor. E9

Tomando como base a ética material dos valores, aprendemos a metafísica na visão de mundo, do homem e do absoluto na medida em que vemos a pessoa como circundada por um cosmo de valores, que em última análise, deve ser reconhecido e descoberto. É importante considerar que o homem é um microcosmo e que "todas as gerações essenciais do ser, o ser físico, químico, vivo, espiritual, se encontram e se cruzam no ser do homem; (...) E por isso, o ser do homem é também o primeiro acesso a Deus"(22:16).

\section{O conhecimento científico: valor lógico no exercício profissional}

O conhecimento científico é uma dimensão sine qua non na formação do enfermeiro e os seus esforços estão voltados para que este conhecimento não seja infringido em sua práxis na medida em que ele recebeu todo um preparo para exercer suas funções e habilidades sempre levando em conta essa exigência em seu manejo laboral. Nesse sentido o conhecimento científico é um valor para o enfermeiro que se relaciona com a dimensão polarizada vida-morte.

Num caso desses você tem que avaliar o doente clinicamente para escolher não tem como ser por questões de caridade ou de sentimento, porque você tem que ter o mesmo sentimento por todos eles, a vontade de ajudar a todos eles.. E1

[...] eu sou muito consciente em todas as coisas que faço. Então quando eu chego para um médico e digo: 'acho que a conduta melhor é essa... '; eu tenho plena certeza do que estou dizendo, [...] para conquistar aquilo que eu acredito que é o correto. E8

[...] se a enfermeira não estudar, ela não sabe argumentar [...] só existe uma forma de você ser respeitado na nossa área, você é o conhecimento que você detém. E9

\section{O amor a Deus: valores religiosos presentes na UTI}

O enfermeiro se mostra afetado pelo amor a Deus como valor, e esse amor que o faz em certa medida nortear condutas éticas como demonstra o depoimento: [E2]Bem, em primeiro lugar, eu acredito em Deus.

O amor é um conceito relevante na medida em que a pessoa humana se caracteriza como ligação entre espírito e vida. Nesse sentido, a vinculação com Deus se dá a partir da unidade, pois Deus é considerado espírito-individual, uma espécie de mar para onde todos os rios tendem. Deve-se buscar a "solidariedade entre todos os seres vivos, até chegar a uma solidariedade universal, que incluísse juntamente o mundo e o próprio Deus"(23). Quando a pessoa tem a intenção de realizar um valor superior, a mesma está adquirindo um valor bom, ou seja, ético para si mesmo. Na Teoria dos Valores, bom é o que se manifesta na realização de outro valor mais alto, sendo que o valor mais pleno em sua hierarquia é o sagrado.

\section{REFLETINDO SOBRE OS VALORES ÉTICOS NA ENFERMA- GEM EM UTI}

Os valores ético-jurídicos foram os mais citados e, no contexto em que aparecem, os valores foram considerados éticos, na intenção de realizar um ato bom. Muitos desses valores eram direcionados ao outro, o paciente. Os valores que constituem o homem são apreendidos pela intuição emocional, por uma vivência. Para a ciência o que não pode ser comprovado por métodos científicos palpáveis, não pode ser considerado como verdade, o que causou um distanciamento da enfermagem do seu fundamento axiológico. Da transgressão de valores éticos surge a desumanização, a desmoralização do homem, a decadência da pessoa que se transforma em objeto.

A enfermagem é a profissão em que os profissionais que a exercem de maneira adequada atingem uma grande capacidade de estabelecer um vínculo com o outro. Por isso, a humanização da assistência requer profissionais éticos, pois é a ética que garante a humanização da assistência. Não se trata somente da ética profissional, estabelecida nos códigos deontológicos, mas uma ética que se inicia a partir de uma tomada de consciência e de vivência de valores superiores. O que precisamos mais do que nunca como profissionais da saúde é de trabalharmos para que se forme "uma nova imagem da constituição essencial do homem", pois como diz o relevante texto a seguir:

[...] as perguntas: o que é o homem? e qual é a sua posição no interior do ser? Ocuparam-me mais essencialmente do que qualquer outra pergunta filosófica. Tenho a satisfação de constatar que os problemas [...] ganharam hoje o ponto central de toda a problemática filosófica [...] e que, muito para além do círculo dos especialistas em filosofia, há biólogos, médicos, psicólogos e sociólogos trabalhando em uma nova imagem da constituição essencial do homem ${ }^{(15)}$.

Atualmente há uma exaltação do materialismo, consumismo, e os valores sensíveis estão sendo superiores aos outros valores e isso é observado na assistência a saúde, em geral, além dos hospitais. Uma ética baseada somente nos valores sensíveis, que para a Teoria dos Valores são inferiores, acaba produzindo o esvaziamento do homem interior. O homem não encontra plenitude de vida ao buscar somente os bens sensíveis e materiais, porém nossa sociedade está repleta dessa realidade a tal ponto que o próprio homem se torna um objeto material a ser consumido.

O enfermeiro, em sua práxis assistencial, deve buscar exercitar a plenitude de vida no amor para uma aproximação aos valores. O amor é considerado na perspectiva scheleriana como sendo "a forma fundamental da experiência dos valores, já que amplia o mundo dos valores da pessoa que constitui seu sujeito, tornando-a sensível para percebê-los afetivamente $^{\prime(24)}$. Pelo ódio, no entanto, há um afastamento do 
mundo objetivo dos valores. No amor o homem descobre os valores e torna-se capaz de optar por valores superiores que visam o bem comum, a valorização de si mesmo e do outro. Através do amor o homem é capaz de optar pelo certo, pelo bom, espontaneamente, livre do dever. O referencial proposto considera a submissão ao Dever como algo desfavorável a construção de um indivíduo ético: "Mandar significa suscitar um Dever a partir do exterior. Porém, visto que o amor é um ato espontâneo, puramente interior e puramente emocional, seria de todo vão suscitá-lo a partir do exterior"(24).

Para a concepção fenomenológica sheleriana, a simpatia ou o amor que se estabelece num relacionamento permite que se conheça efetivamente a essência do homem e possibilita uma comunicação plena entre as pessoas. Esse relacionamento, que o enfermeiro estabelece rotineiramente para cuidar, é que efetivamente o torna capaz de conhecer e atender a necessidade do outro, e que afasta o estabelecimento de condutas terapêuticas inapropriadas baseadas somente nos aspectos biológicos, racionais e científicos que não contemplam o homem plenamente. Nesse sentido, destaca-se a solidariedade que envolve o amor pelo próximo, pelo presente, pelo aqui e agora evidenciando a importância da preservação do ser, a continuidade da vida. É uma transcendência imanente, uma aura, um valor englobante. É uma ética que serve de cimento aos diferentes grupos que atuam no mesmo espaço e tempo ${ }^{(25)}$.

É importante o enfermeiro considerar que a percepção do outro, mediada pela simpatia e pelo amor, possibilita a identificação de valores pessoais do outro e de si mesmo. A Teoria dos Valores preconiza que "só pelo amor podemos chegar à realidade da pessoa que constitui o núcleo ontológico do outro. Por outros meios, como os racionais e científicos, podemos conhecer o caráter e o temperamento, nunca a pessoa do outro". Pelos métodos racionais e científicos não identificamos a pessoa, mas somente dados, sinais e particularidades, e se ignora a que indivíduo pertencem ${ }^{(12)}$. A fenomenologia sheleriana afirma essa questão da seguinte maneira: "Ora, a pessoa individual não nos é dada senão no ato de amor, e seu valor, enquanto valor individual não se nos revela senão através desse ato" ${ }^{\prime 15)}$. Somando-se aos valores que permeiam as condutas profissionais na UTI, a humildade como valor vital, foi também destacada no estudo. Na verdade, os valores vitais não são reduzidos ao valor de coisa, pois que o vital e a vida mesma não podem ser reduzidos a um conceito como uma coisa. Como estados, se referem aos modos de sentimento vital como o sentimento de saúde, doença; vigor, esgotamento. Como reações sentimentais, o contentar-se, afligir-se; como reações instintivas, a angústia, a vingança, a cólera, etc. Não podem, portanto, ser reduzidos ao valor de coisas agradáveis, nem estão à altura de valores espirituais ${ }^{(26)}$.

Um vínculo baseado na simpatia e no amor favorece aos profissionais adquirirem valores superiores e esses valores superiores visam atender o outro mais humanamente. Por isso entende-se o discurso que aparece repetido: o respeito aliado ao conhecimento científico. $\mathrm{O}$ respeito e a dignidade, dentre os valores espirituais ou culturais da Teoria em questão, são fundamentais nas relações profissionais da equipe de saúde especialmente em meio a situações conflituosas de condutas que permeiam o cuidado e a terapêutica do paciente. Para existir o respeito, é preciso haver uma relação que permita o conhecimento do outro, o conhecimento de sua essência, de seus valores. Essa relação é permeada pelo amor que permite a comunicação, a experiência da singularidade do outro. $\mathrm{O}$ amor traz o desejo de conhecer e quando amamos também valorizamos.

Nesse sentido é importante ressaltar que a práxis de saúde ocorre num esforço coletivo e cooperativo, entre sujeitos, numa rede de relações que exige interação e diálogo permanentes. Portanto, no trabalho em saúde especialmente, no cuidado de Enfermagem, torna-se fundamental cuidar dessa rede de relações permeada por assimetrias de saber e de poder $^{(27)}$. Por certo, o respeito, a dignidade e a justiça, dentre os valores ético-jurídicos, e o conhecimento científico, dentre os valores lógicos, são considerados valores superiores que permitem a realização de um cuidado que satisfaz as necessidades do homem por inteiro e não em partes, levando-se em conta dimensão maior da ordem do cultural e espiritual em que estão inseridos. Percebe-se, também, que qualquer valor que não é direcionado para o bem do homem torna-se um valor perdido.

O conhecimento científico, também no âmbito dos valores culturais na Teoria dos Valores, foi ressaltado no estudo, consistindo diferencial marcante no discurso profissional em meio à prática, tornando-se fator preponderante em UTI e especialmente em questões conflituosas que envolvem vida e morte. No entanto, devido à concepção positivista, o conhecimento só é considerado verídico quando é isento das interferências do sujeito e de suas valorações e os atos emocionais são desconsiderados por não permitirem o alcance de um conhecimento autêntico, segundo seus métodos. $\mathrm{O}$ pensamento scheleriano a respeito disso afirma que: "Deve-se levar em conta que essa concepção procede da ignorância, essencialmente positivista, da íntima unidade que vincula, na experiência, o valor do objeto com os atos emocionais"(28)

Certamente, o conhecimento científico, a razão, os dados clínicos mensuráveis, são essenciais para o alcance da verdade e é fundamental para realizar um cuidado eficaz. Porém, o cuidado, de enfermagem ou de medicina, é para a pessoa e não para um objeto material. Realizar um cuidado com uma pessoa sem considerar a importância de estabelecer uma relação de respeito é realizar uma assistência mecanizada, é tratar a pessoa como um objeto, é estabelecer relações amorais. $\mathrm{O}$ cuidado baseado só no conhecimento técnico-científico não satisfaz as necessidades do homem. É preciso lembrar que: "fazer enfermagem é fazer-se dentro do contexto da saúde e da cultura"(29:1169). Por esta razão, torna-se oportuno o alerta para o fato de que:

[...] são as universidades, que alicerçadas no tripé ensino/ pesquisa/extensão, [...] possam oportunizar intervenções capazes de mobilizar, o ser-com-os-outros, a intersubjetividade, a autenticidade, a solicitude e o desvelo, para que estes se reflitam nas decisões e nos cuidados planejados e desenvolvidos com vista à assistência integral e humanizada na área de saúde(31). 
Enfim, cabe destacar que, no cotidiano profissional, situações éticas coexistem confrontando o enfermeiro por vezes em ocorrências inesperadas. Nesses momentos, isolar e separar o homem do seu contato imediato com a existência e a vida, com o fundamento de todas as coisas, significa uma limitação terrível do homem ${ }^{(31)}$. Não obstante serem, em grande parte, inevitáveis, não há como recuar ou isolar-se dessas ocorrências; pelo contrário, deve-se possibilitar abertura para uma discussão interdisciplinar dessas questões que perpassam as profissões ligadas ao paciente, resgatando e repensando concepções próprias que se fundam como valor em cada ser, e que permearão as condutas diante de intercorrência ética.

\section{CONCLUSÃO}

O estudo evidencia que os enfermeiros apresentam uma singular capacidade de adquirir valores superiores por meio do exercício de cuidar do outro. As teorias filosóficas são importantes na medida em que ajudam a compreender o que é o cuidado e o homem. Conhecer o homem faz parte do cuidar, do cuidar do outro e do cuidar de si. Nesse sentido, a Teoria dos Valores pode contribuir como uma filosofia singular para os profissionais de saúde no âmbito de situações de dilemas éticos vivenciados especialmente em unidades de alta complexidade como UTI, possibilitando rever valores pessoais de vida e repensar suas condutas. Além disso, pode constituir importante fonte de inspiração para a enfermagem por permitir a abordagem de uma ética humanizadora no cuidado à saúde.

As contribuições do estudo se evidenciam na medida em que as situações que envolvem dilemas éticos no cotidiano profissional são frequentes e permeiam a práxis não só do enfermeiro, mas dos demais membros da equipe de saúde, especialmente os que exercem sua atividade laboral em Unidades de Terapia Intensiva, requerendo por parte do profissional um fortalecimento acerca dos valores interiores já que nortearão sua conduta na escolha de caminhos decisivos diante de cada situação ética conflitante. É preciso que os enfermeiros fundamentem seus valores a partir de uma reflexão profunda, no individual e no coletivo, para que, descobrindo-se como um sujeito de valor, torne-se capaz de defender o valor do outro em sua prática.

\section{REFERÊNCIAS}

1. Chaves AAB, Massarollo MCKB. Percepção de enfermeiros sobre dilemas éticos relacionados a pacientes terminais em Unidades de Terapia Intensiva. Rev Esc Enferm USP 2009;43(1):30-6.

2. Pessini L, Barchifontaine CP. Fundamentos da bioética. São Paulo: Paulus; 1996.

3. Silva MF, Fernandes MFP. A ética ante o gerenciamento de enfermagem em cuidado paliativo. Mundo da Saúde 2006;30(2):318-25.

4. Ministério da Saúde (Brasil) Secretaria de Vigilância Sanitária. Portaria no 466, de 04 de junho de 1998. Regulamento Técnico para o funcionamento dos serviços de tratamento intensivo. Diário Oficial da União 09 abr 2001.

5. Pessini L. Distanásia: até quando prolongar a vida? São Paulo: Loyola; 2001.

6. Toffoletto MC, Zanei SSV, Hora E, Nogueira GP, Miyadahira AK, Kimura $M$, et al. A distanásia como geradora de dilemas éticos nas Unidades de Terapia Intensiva: considerações sobre a participação dos enfermeiros. Acta Paul Enferm 2005;18(3):307-12.

7. Tucker DLM, Friedson J. Resolving moral conflict: the critical care nurses role. Crit Care Nurs 1997;17(2):55-63.

8. Antunes AV, Trevizan MA. Gerenciamento da qualidade: utilização no serviço de enfermagem. Rev Latinoam Enferm 2000;8(1):35-44.

9. Richer J, Eisemann MR. Attitudinal patterns determining decision-making in the treatment of the elderly: a comparison between physicians and nurses in Germany and Sweden. Intensive Care Med 2000;26(9):1326-33.

10. Alarcos MFJ. Bioética e pastoral da saúde. São Paulo: Paulinas; 2006.
11. Arruda CS, Nogueira E, Oliveira MS, Pereira ER, Silva RMCA. Avanços e desafios da enfermagem na produção científica sobre psoríase. Rev Bras Enferm 2010;63(2):264-73.

12. Costa JS. Max Scheler: o personalismo ético. São Paulo: Moderna; 1996.

13. Guimarães GL, Viana LO. O valor ético no ensino da enfermagem. Esc Anna Nery Rev Enferm 2009;13(3):517-22.

14. Reale G, Antiseseri D. História da filosofia. Vol. VI. 2ed. São Paulo: Paulus; 2006

15. Scheler M. Nature et formes de la sympathie [1950]. Paris: Payot; 2003.

16. Leopardi MT. Metodologia da pesquisa na saúde. Santa Maria: Pallotti; 2001.

17. Secco LM, Castilho V. Levantamento do custo do procedimento de hemodiálise veno-venosa contínua em unidades de terapia intensiva. Rev Latinoam Enferm 2007;15(6):1138-43.

18. Scheler M. Da reviravolta dos valores: Ensaios e textos. Petrópolis, Brasil: Vozes; 1994.

19. Brasil. Constituição da República Federativa do Brasil. São Paulo: IMESP; 1988.

20. Conselho Federal de Medicina (Brasil) Resolução CFM No 1931/2009 de 29 de setembro de 2009. Código de Ética Médica . Diário Oficial da União 29 set 2009; Seção 1.

21. Conselho Federal de Enfermagem (Brasil) Resolução COFEN No 311/2007 de 08 de fevereiro de 2007. Código de Ética da Enfermagem Brasileira. Diário Oficial da União 13 de fev 2007; Seção 1.

22. Scheler M.Visão filosófica do mundo. São Paulo: Perspectiva; 1986. 
23. Abbagnano N. Dicionário de filosofia. 5. ed. São Paulo: Martins Fontes; 2007.

24. Wojtyla K. Max Scheler e a ética cristã. Curitiba: Champagnat; 1993.

25. Martini JG. Mas, do que é mesmo que estamos falando quando abordamos a integralidade? Rev Bras Enferm 2008;61(3):285.

26. Volkmer SAJ. O perceber do valor na ética material de Max Scheler. Dissertação [Mestrado em Filosofia]- Faculdade de Filosofia e Ciências Humanas, PUCRS; 2006.

27. Pereima RSMR, Reibnitz KS, Martini JG, Nitschke RG.
Doação de sangue: solidariedade mecânica versus solidariedade orgânica. Rev Bras Enferm 2010;63(2):322-7.

28. Scheler M. Amour et connaissance. Paris: Aubir; 1951.

29. Silva RMCRA, Pereira ER, Santo FHE, Silva MA. Cultura, saúde e enfermagem: o saber, o direito e o fazer crítico-humano. Rev Eletrônica Enferm 2008;10(4):1165-71.

30. Salimena AMO, Souza IEO. Cotidiano da mulher pós-histerectomia à luz do pensamento de Heidegger. Rev Bras Enferm 2010;63(2):196-202.

31. Scheler M. Conocimiento y trabajo. Buenos Aires: Nova; 1969. 